\title{
Reappearance of Risk of Schistosomiasis Transmission and the Response After 27 Years of Interrupted Transmission - Guangdong Province, China, 2019
}

\author{
Shaoyu Huang'; Qiang Mao'; Qili Zhong²; Xiuhong Fan³ ${ }^{3}$ Weiquan $\mathrm{Li}^{4}$; \\ Yonghua Rao'; Fuquan Pei'; Shizhu Li ${ }^{6}$; Zhuohui Deng ${ }^{1, *}$
}

\section{Summary}

What is already known about this topic?

No live specimens of the snail Oncomelania hupensis (O. hupensis) and indigenous infected cases of schistosomiasis japonicum have been found in Guangdong Province since 1993, but live O. hupensis was found again in 2019. This study conducted $O$. hupensis identification and elimination.

What is added by this report?

In 2019, live $O$. hupensis specimens were detected by routine surveillance in areas in Qujiang of Shaoguan City and Yingde of Qingyuan City, and an emergency response was launched immediately.

What are the implications for public health practice?

The suspected habitat of $O$. hupensis in originally endemic areas of schistosomiasis in Guangdong is still complicated, so it is necessary to record suspected habitats comprehensively and carry out scientific routine surveillance for $O$. hupensis.

Oncomelania hupensis (O. hupensis) is the only intermediate host of Schistosoma japonicum (1). Guangdong Province is also a province with endemic $O$. hupensis, and there used to be an estimated 110 million square meters of original habitat for $O$. hupensis (2). In order to eliminate schistosomiasis, a team in Guangdong modified the environment to undertake O. hupensis control measures, and since 1993, live O. hupensis have disappeared in Guangdong (3). Unexpectedly, live $O$. hupensis were found during the spring $O$. hupensis survey in Qujiang District of Shaoguan City and Yingde City of Qingyuan City of Guangdong in early April of 2019 (Figure 1). In order to maintain the state of no live $O$. hupensis in Guangdong Province and to eliminate the risk of possible recurrence of schistosomiasis, a team in Guangdong was dispatched to carry out prevention and control measures to eliminate $O$. hupensis and modify its breeding area from April to August 2019 in this study.

The first $O$. hupensis habitat area was located in the junction area of Changjiang Dam of Shakou Town, Yingde (county-level jurisdiction), Qingyuan City, and Qunxing Village of Zhangshi Town, Qujiang District (county-level jurisdiction), Shaoguan City, which was originally an $O$. hupensis habitat area (Figure 1), with diverse and complex surrounding environments. The O. hupensis density survey was carried out by 5 meter systematic sampling combined with 2-frame environmental sampling. Both dead and live snails were identified, and the infection rate of Schistosoma japonicum cercariae in live snails was detected by anatomical microscope, polymerase chain reaction (PCR), and loop-mediated isothermal amplification (4). At the same time, the whole mitochondrial genome DNA of snails was sequenced and phylogenetic analysis was carried out using next generation sequencing. In order to further understand the schistosomiasis infection status of people and livestock in the affected areas, the venous blood and feces of people and cattle were collected, and schistosomiasis antibodies were detected for using indirect haemagglutination assay (IHA). The feces were detected by metacercaria incubation method and Kato Katz. In addition, in order to completely eliminate the snails, comprehensive environmental treatment was adopted in the response process. The main measures include the following: comprehensively managing ditches by weeding and clearing the surface; spraying the area with $26 \%$ metaldehyde and niclosamide suspension concentrate combined with either black ground rubber film cover or with soaking to eliminate $O$. hupensis; and filling old ditches and constructing new ditches and hardening three sides with smooth surfaces.

The results showed a total of 1,847 suspected 


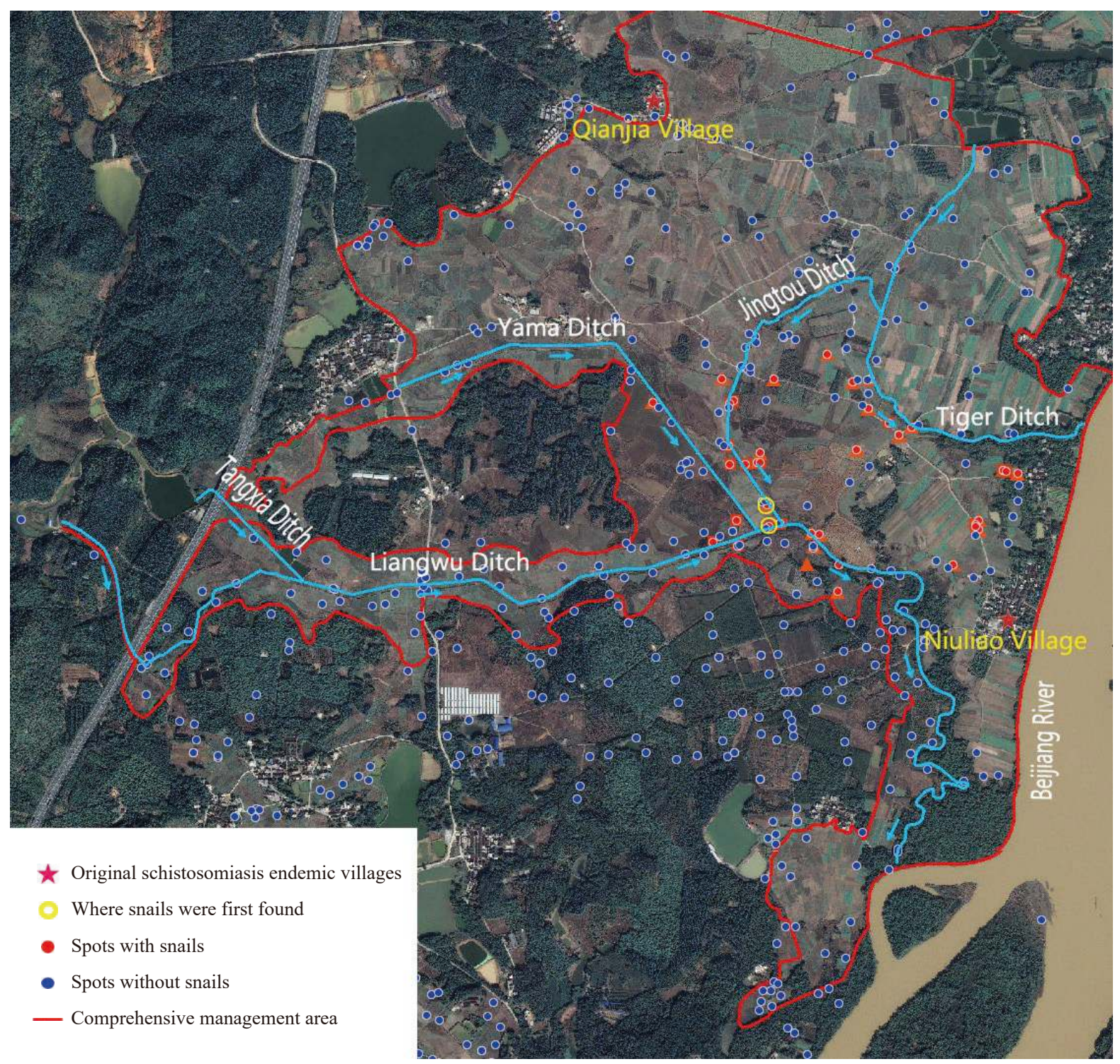

FIGURE 1. The map of comprehensive management of Oncomelania hupensis in Guangdong Province in 2019.

environments suitable for $O$. hupensis habitat that were investigated, with a total area of about 2.26 million square meters. A total of 40 environments with $O$. hupensis were identified covering an area of about 124.7 thousand square meters. The occurrence rate of the survey frames with $O$. hupensis in the habitat environment was $0.32 \%-66.09 \%$, and the density of live $O$. hupensis was $0.01-7.66 /$ frame (Table 1). A total of 8,612 snails were collected and identified as live snails. The whole mitochondrial genome sequence $(15,850 \mathrm{bp})$ of $O$. hupensis was obtained by secondgeneration deep sequencing. The results of identification and evolutionary analysis showed that O. hupensis in Guangdong Province and the Yangzhou (JF284688.1) strain in Jiangsu Province were located in the same evolutionary branch, and identification with the strain at the nucleotide level was $100 \%$ (Figure 2). A total of 4,861 human blood samples were collected, with a test response rate of more than $95 \%$. The IHA test results were positive for schistosomiasis antibody in 14 people $(0.29 \%)$, and the stool samples of 14 IHA positive people were negative for schistosomiasis eggs and metacercaria. The blood and fecal samples of 269 buffalo in all affected areas were collected, and the examination rate was $100 \%$. No Schistosoma antibodies, eggs, and cercariae were found. In the process of environmental treatment, a total of $51.94 \mathrm{~km}$ of canals were newly built and repaired, 3 screw basins were newly built, 27 culverts were rebuilt, and more than 3,000 acres of farmland remediation and rehabilitation were completed. The cumulative drug snail extermination area was 1.45 million square 
TABLE 1. Investigation on Oncomelania hupensis and its breeding area in the affected areas of Qujiang and Yingde, Guangdong Province from April to August 2019.

\begin{tabular}{|c|c|c|c|c|c|c|c|c|}
\hline $\begin{array}{l}\text { County-level } \\
\text { jurisdiction }\end{array}$ & $\begin{array}{l}\text { No. of snail } \\
\text { environment }\end{array}$ & $\begin{array}{c}\text { Environment } \\
\text { type }\end{array}$ & $\begin{array}{l}\text { Environmental } \\
\text { area }\left(\mathrm{m}^{2}\right)\end{array}$ & $\begin{array}{c}\text { No. of survey } \\
\text { system } \\
\text { frames }\end{array}$ & $\begin{array}{l}\text { No. of live } \\
\text { snail frames }\end{array}$ & $\begin{array}{c}\text { Rate of live } \\
\text { snail frames }\end{array}$ & $\begin{array}{l}\text { No. of live } \\
\text { snails } \\
\text { collected }\end{array}$ & $\begin{array}{c}\text { Live } \\
\text { Oncomelania } \\
\text { density } \\
\text { (No./ frame) }\end{array}$ \\
\hline Qujiang & 1 & Ditch & 78 & 43 & 6 & 13.95 & 147 & 3.42 \\
\hline Qujiang & 2 & Ditch & 1,575 & 12 & 1 & 8.33 & 1 & 0.08 \\
\hline Qujiang & 3 & Ditch & 400 & 23 & 5 & 21.74 & 11 & 0.48 \\
\hline Qujiang & 4 & Ditch & 800 & 174 & 115 & 66.09 & 794 & 4.56 \\
\hline Qujiang & 5 & Ditch & 60 & 26 & 1 & 3.85 & 1 & 0.04 \\
\hline Qujiang & 6 & Waste land & 865 & 66 & 1 & 1.52 & 1 & 0.02 \\
\hline Qujiang & 7 & Waste land & 5,004 & 133 & 2 & 1.50 & 2 & 0.02 \\
\hline Qujiang & 8 & Ditch & 50 & 13 & 2 & 15.38 & 5 & 0.38 \\
\hline Qujiang & 9 & Ditch & 50 & 12 & 4 & 33.33 & 20 & 1.67 \\
\hline Qujiang & 10 & Ditch & 320 & 308 & 1 & 0.32 & 17 & 0.06 \\
\hline Qujiang & 11 & Ditch & 65 & 28 & 4 & 14.29 & 16 & 0.57 \\
\hline Qujiang & 12 & Ditch & 175 & 33 & 3 & 9.09 & 6 & 0.18 \\
\hline Qujiang & 13 & Waste land & 2,200 & 262 & 4 & 1.53 & 16 & 0.06 \\
\hline Qujiang & 14 & Ditch & 240 & 83 & 1 & 1.20 & 1 & 0.01 \\
\hline Qujiang & 15 & Waste land & 30 & 11 & 3 & 27.27 & 15 & 1.36 \\
\hline Qujiang & 16 & Waste land & 50 & 11 & 2 & 18.18 & 15 & 1.36 \\
\hline Qujiang & 17 & Waste land & 7,178 & 414 & 54 & 13.04 & 97 & 0.23 \\
\hline Yingde & 18 & Waste land & 10,525 & 32 & 11 & 34.38 & 164 & 5.13 \\
\hline Yingde & 19 & Ditch & 1,592 & 31 & 8 & 25.81 & 63 & 2.03 \\
\hline Yingde & 20 & Waste land & 22,056 & 55 & 17 & 30.91 & 179 & 3.25 \\
\hline Yingde & 21 & Waste land & 2,653 & 111 & 26 & 23.42 & 144 & 1.30 \\
\hline Yingde & 22 & Waste land & 1,781 & 70 & 25 & 35.17 & 154 & 2.20 \\
\hline Yingde & 23 & Waste land & 2,164 & 77 & 7 & 9.09 & 590 & 7.66 \\
\hline Yingde & 24 & Waste land & 7,676 & 77 & 12 & 15.58 & 28 & 0.36 \\
\hline Yingde & 25 & Waste land & 13,603 & 98 & 21 & 21.43 & 300 & 3.06 \\
\hline Yingde & 26 & Waste land & 8,935 & 36 & 11 & 30.56 & 28 & 0.78 \\
\hline Yingde & 27 & Waste land & 2,175 & 73 & 5 & 6.85 & 25 & 0.34 \\
\hline Yingde & 28 & Ditch & 4,064 & 138 & 11 & 7.97 & 37 & 0.27 \\
\hline Yingde & 29 & Waste land & 1,752 & 17 & 2 & 11.76 & 13 & 0.76 \\
\hline Yingde & 30 & Waste land & 337 & 18 & 8 & 44.44 & 90 & 5.00 \\
\hline Yingde & 31 & Ditch & 259 & 99 & 42 & 42.42 & 629 & 6.35 \\
\hline Yingde & 32 & Waste land & 10,599 & 347 & 18 & 5.19 & 89 & 0.26 \\
\hline Yingde & 33 & Waste land & 6,215 & 147 & 4 & 2.72 & 33 & 0.22 \\
\hline Yingde & 34 & Waste land & 6,245 & 162 & 10 & 6.17 & 189 & 1.17 \\
\hline Yingde & 35 & Ditch & 278 & 175 & 102 & 58.29 & 726 & 4.15 \\
\hline Yingde & 36 & Ditch & 250 & 43 & 8 & 18.60 & 25 & 0.58 \\
\hline Yingde & 37 & Ditch & 620 & 169 & 1 & 0.59 & 1 & 0.01 \\
\hline Yingde & 38 & Ditch & 1,370 & 238 & 44 & 18.49 & 1,312 & 5.51 \\
\hline Yingde & 39 & Ditch & 200 & 35 & 20 & 57.14 & 76 & 2.17 \\
\hline Yingde & 40 & Ditch & 300 & 107 & 1 & 0.93 & 1 & 0.01 \\
\hline Total & & & 124,789 & 4,007 & 623 & 15.55 & 6,061 & 1.51 \\
\hline
\end{tabular}




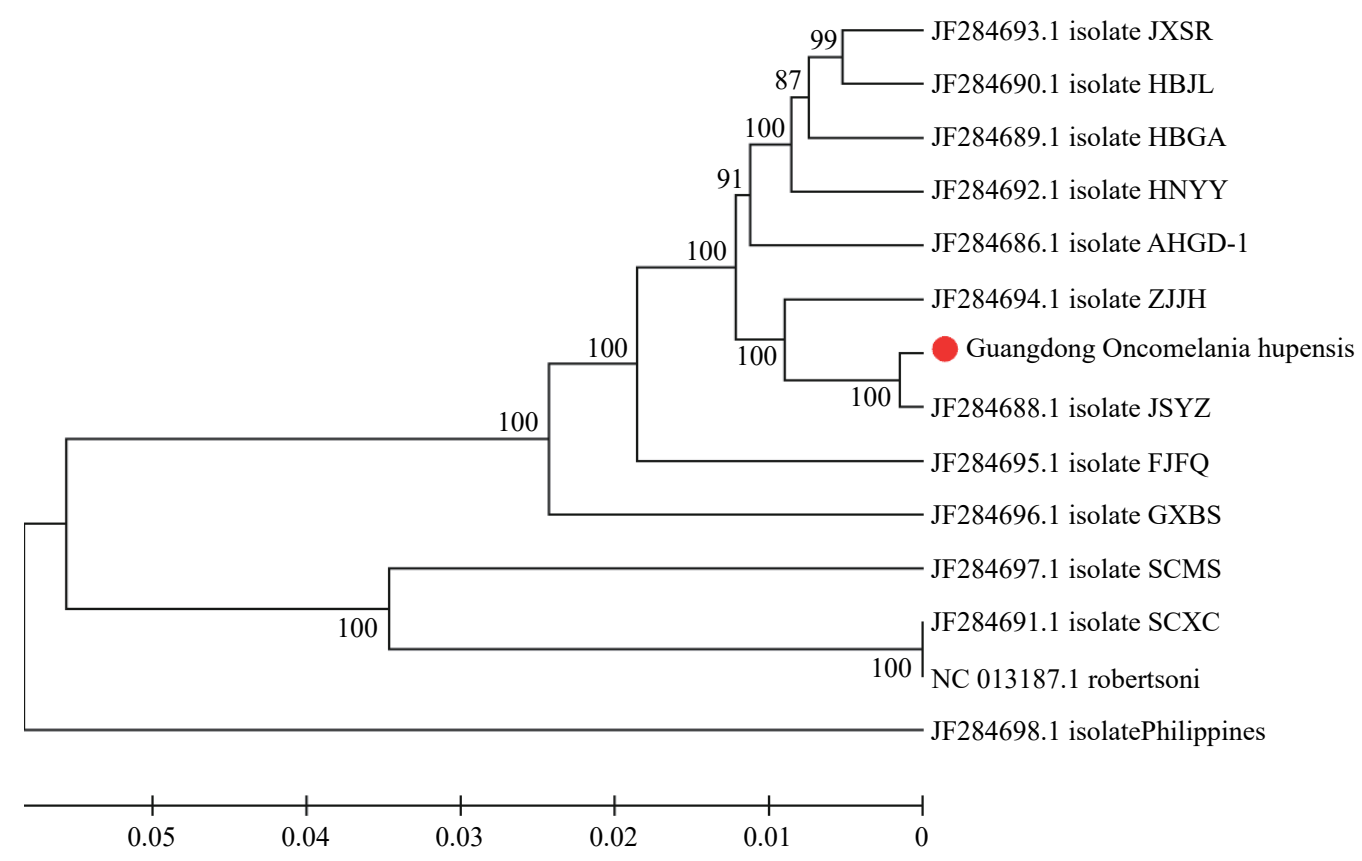

FIGURE 2. Phylogenetic tree of Oncomelania hupensis mitochondrial genomic DNA obtained from Qujiang in 2019 in Guangdong Province, China.

Notes: A total of 14 sequences were used for phylogenetic tree reconstructions. The Guangdong Oncomelania hupensis strain was indicated by red circle.

meters. From December 2020 to May 2021, 40 environments with $O$. hupensis and the surrounding environments were monitored and evaluated several times, and no more live O. hupensis were detected.

\section{DISCUSSION}

Schistosomiasis epidemic areas in Guangdong Province were mainly distributed in the middle and lower reaches of the Beijiang River in the Pearl River System (2). Guangdong Province announced the elimination of schistosomiasis in 1985 as there were no O. hupensis found in 7 years. Since then, in 1992, an outbreak of $O$. hupensis reappeared in Caozhai Village, Sanshui District, Foshan City. It was found that there were $2000 \mathrm{~m}^{2}$ of $O$. hupensis and 3 persons with positive fecal eggs, including 1 case of previous infection and 2 cases of new infection (5). No $O$. hupensis had been reported in affected area in Yingde since 1982, and no sick cattle have been found since 1983 (5). Fortunately, we did not find any human and animal infections, so we inferred that the possible reasons for the recurrence of $O$. hupensis were as follows. First, there might be some remaining $O$. hupensis still living in the local environments at that time, and the environmental conditions were suitable for the reproduction of $O$. hupensis, which reached a certain density after many years. Second, the environment was low-lying and waterlogged during the flood season, resulting in abandoned fields and overgrown weeds, forming an environment suitable for $O$. hupensis habitation. Third, the environmental terrain and its altitude, the mode of production and grazing, etc., were all possible factors causing $O$. hupensis to spread in a large area in this region. Fourth, the local reporting of suspicious environment suitable for $O$. hupensis habitat was not comprehensive enough, which might have resulted in insufficient monitoring coverage and missed investigation for many years (6). In 2018, Yingde strengthened the reporting efforts and monitored the environment of the newly built datasets in 2018, subsequently finding the $O$. hupensis habitats. Of the 40 areas affected by $O$. hupensis, half were distributed along the water system, and the other half were distributed at independent points. It is analyzed that the habitat and diffusion of the remaining snails in this area might be categorized in three passive diffusion modes (7): 1) carried and spread by water flow along the river system, flooding, and waterlogging water; 2) carried by human production and living activities; and 3) carried by activity of grazing animals in affected areas.

The following points were learned and implemented in this emergency response: 1) the monitoring system 
must be maintained and be effective by adhering to surveillance procedures, team training, and quality evaluation every year; 2) the reoccurrence of the $O$. hupensis epidemic was confirmed quickly, and the provincial, municipal and county levels immediately launched emergency response, quickly established multidepartment joint management mechanisms, and took emergency implementation measures; 3) according to the characteristics of the environments with $O$. hupensis, molluscacide was utilized with environmental reforms to eliminate $O$. hupensis rapidly and consolidate the effects of $O$. hupensis eradication; 4) environments containing O. hupensis, surrounding water systems, and suspected environments must be comprehensively managed to reduce suspected environments suitable for $O$. hupensis breeding and minimize the risk of $O$. hupensis breeding and diffusion in the affected places, and relevant departments must be synchronized and collaborate on their work.

There are some limitations in the snail disposal. Firstly, the limitation of snail traceability. At present, there is no whole genome sequence of oncomelania, so it can only be compared according to the mitochondrial genome sequence. Secondly, the limitation of snail distribution survey. Based on the current method of snail investigation, probability of missing inspection is high in the environment with low density; There may also be very few residual snails in the environment after snail disposal.

Strengthening surveillance is an important measure to consolidate and eliminate schistosomiasis. In order to consolidate the O. hupensis control effect, it is necessary to further strengthen the effect evaluation and monitoring, improve the environmental management, and conduct sustainable environmental management. In schistosomiasis surveillance areas, it is necessary to further strengthen the comprehensive reporting and registration of suspected environments suitable for $O$. hupensis habitation, strive to fully grasp the distribution and quantity of suspicious habitat environments, simultaneously carry out dynamic filing management, carry out rational $O$. hupensis monitoring, ensure monitoring coverage and $O$. hupensis survey quality, and prevent missing investigations.

doi: $10.46234 / \mathrm{ccdcw} 2021.264$

\# Corresponding author: Zhuohui Deng, zhdeng@cdcp.org.cn. ${ }^{1}$ Guangdong Provincial Center for Disease Control and Prevention,
WHO Collaborating Centre for Surveillance, Research and Training of
Emerging Infectious Diseases, Guangzhou, Guangdong, China;
${ }^{2}$ Shaoguan Center for Disease Control and Prevention, Shaoguan,
Guangdong, China; ${ }^{3}$ Qingyuan Center for Disease Control and
Prevention, Qingyuan, Guangdong, China; ${ }^{4}$ Yingde Center for
Disease Control and Prevention, Qingyuan, Guangdong, China;
Qujiang Center for Disease Control and Prevention, Shaoguan,
Guangdong, China; ${ }^{6}$ National institute of parasitic diseases Chinese
Center for Disease Control and Prevention, Shanghai, China.

Submitted: August 28, 2021; Accepted: December 15, 2021

\section{REFERENCES}

1. Feng XY, Zhu LQ, Qin ZQ, Mo XJ, Hao YW, Jiang Y, et al. Temporal transcriptome change of Oncomelania hupensis revealed by Schistosoma japonicum invasion. Cell Biosci 2020;10:58. http://dx.doi.org/10.1186/ s13578-020-00420-4.

2. Rong SM, Liu JS, Chen PJ. Measures and effects of Oncomelania hupensis eradication in Guangdong Province. Chin J Schisto Control 1993;5(5):299 - 300. http://dx.doi.org/10.16250/j.32.1374.1993.05. 024. (In Chinese).

3. Rong SM, Liu JS, Chen PJ. Observation and analysis of residual Oncomelania hupensis in Guangdong Province. Chin J Schisto Control 1996;8(5):294 - 5. http://dx.doi.org/10.16250/j.32.1374.1996.05.017. (In Chinese).

4. Qin ZQ, Xu J, Feng T, Lv S, Qian YJ, Zhang LJ, et al. Field evaluation of a loop-mediated isothermal amplification (LAMP) platform for the detection of Schistosoma japonicum infection in Oncomelania hupensis snails. Trop Med Infect Dis 2018;3(4):124. http://dx.doi.org/10.3390/ tropicalmed3040124.

5. Huang F. Prevalence and control of schistosomiasis in Guangdong Province. Guangzhou: Guangdong Science and Technology Press. 2005; p. 120. https://book.kongfz.com/180897/3622361877/. (In Chinese).

6. Liu HX, Zhang Y, Hu L, Wu Y, Lv S, Guo JG, et al. Analysis of reemergence of Oncomelania hupensis in area where schistosomiasis transmission-interrupted in China. J Pathog Biol 2008;3(6):440 - 2,446. http://dx.doi.org/10.13350/j.cjpb.2008.06.008. (In Chinese).

7. Zhou XN. Science on oncomelania snail. Beijing: Science Press. 2005; p. 154-6. https://book.kongfz.com/12410/3033475605/. (In Chinese). 